\title{
Determinants of under-five mortality in Gilgel Gibe Field Research Center, Southwest Ethiopia
}

\author{
Amare Deribew ${ }^{1}$, Fasil Tessema ${ }^{2}$, Belaineh Girma ${ }^{3}$
}

\begin{abstract}
Background: In developing countries like Ethiopia where there is no vital events registration system and laboratory diagnosis is lacking, causes of death in under-five children and its determinants could not be well known. The objective of this study was to investigate causes of death and its determinants in under-five children in Gilgel Gibe Field Research Center.

Methods: A case-control study was conducted from December 12 to 27, 2005. Cases of under-five children who died between August 27, 2004 and September 22, 2005 and controls of alive children with the same age (+/-2 months) as cases were identified by a survey as the study population. Data were collected by trained enumerators using structured questionnaire adopted from World Health Organization (WHO). Causes of death were determined using the expert algorithm based on verbal autopsy data.

Results: Neonatal and infant mortality rates were respectively 38 and 76.4 per 1000 live births. The two most common causes of death during neonatal period were prematurity (26.4\%) and pneumonia (22.6\%). Whereas the top causes of death in post-neonatal period were pneumonia (42\%), malaria (37\%) and acute diarrheal diseases (30\%). Maternal education, practice and perception of mothers on the severity of illness and benefits of modern treatment were found to be independent predictor of child survival.

Conclusion: Neonatal causes, pneumonia, malaria and diarrheal diseases were the major killers of under-five children in Ethiopia. In this study, practice of mothers and perceived benefits on the modern treatment are identified as the key predictors of child survival which are amenable to future intervention. [Ethiop.J.Health Dev. 2007;21(2):117-124]
\end{abstract}

\section{Introduction}

The $20^{\text {th }}$ century witnessed dramatic decline in under-five mortality in almost all countries of the world, regardless of initial levels, socio-economic circumstances and development strategies. However, more than 10.8 million children younger than 5 years die every year mostly from preventable causes. Six countries accounted for $50 \%$ of worldwide deaths in children younger than five and 42 countries for $90 \%$ (1). Child mortality varies among world regions, and these differences are becoming wide. In 2000, there were 175 deaths per 1000 live births in Sub-Saharan Africa and only 6 per 1000 in the industrialized countries, which is a 29 fold difference (1, 2).

In Ethiopia under-five mortality rate is among the highest in the world. Nearly one out of 10 babies born in Ethiopia does not survive to celebrate its first birthday. One out of every six children dies before the fifth birthday $(3,4)$.

In 2000, as part of the millennium development goals for health, nations pledged to ensure a two-third reduction in child mortality by 2015, from the base year 1990(5). To achieve these goals, understanding of determinants of under-five mortality and implementing appropriate intervention is expected from each nations of the world. Determinants of mortality can be depicted using conceptual framework developed by Mosley and Chen. This framework consisted of socio-economic and proximate determinants (6). The socio-economic determinants such as income, social status and education indirectly affect under-five mortality through the operation of proximate determinants of maternal factors like (age, parity, birth order etc...), and as well as environmental, nutritional, injury and behavioral factors (6).

To plan and implement child survival interventions, the socio-economic and proximate determinants should be measured through population-based researches. Causes of under-five death and the determinants are not well explored in Ethiopia. This study was conducted to fill this gap with the objective of assessing causes of underfive deaths and the determinants in a community setting at Gilgel Gibe Field Research Center.

\section{Methods}

A case-control study was conducted from December 12 to 27, 2005 at Gilgel Gibe Field Research Center. Gilgel Gibe Field Research Center is located in Jimma Zone of Oromiya regional state about 260 Kilo meter $(\mathrm{Km})$ Southwest of Addis Ababa and about 55 K.m Northeast of Jimma Town around the reservoir of Gilgel Gibe Hydroelectric dam. The site is bounded by four woredas: Sekuru, Omo-Nada, Tiro- Afeta and Kersa. One small town and eight rural kebeles (smallest administrative units), which are found within 10 kilometer of the reservoir of the dam were already selected by Jimma

${ }^{1}$ Department of Epidemiology and Biostatistics, Jimma University, P.O.Box 205, Jimma, E-mail: amare deribew@ yahoo.com; ${ }^{2}$ Department of Epidemiology and Biostatistics, Jimma University, P.O.Box 378, Jimma; ${ }^{3}$ Department of Monitoring and Evaluation, Jimma University, E-mail: belainehg@yahoo.com 
University from the four woredas as the field research center. Baseline survey of the Field Research Center was undertaken from August 27 to September 22, $2005(7,8)$. In the study area the total population was 42,290 with having 8,859 households. Of the total population under- 5 children constituted $17 \%$ (8).

The source population was all under- five children around Gilgel Gibe Field Research Center. Whereas the study population consisted of cases of under five-children who died in the period between August 27, 2004 and September 22, 2005 and live controls of the same age (+/-2 months).

The sample size was calculated using Epi-Info 6.04 statistical software by considering that the proportion of poor mothers among the controls of $74 \%$ (main exposure variable) which is estimated from other study (9), $95 \%$ CI, $80 \%$ power of the study and control to case ratio of $1: 1$ to detect an odds ratio of 2.27 which is estimated from a study done by others (10). Accordingly, 171 cases and 171 controls (a total sample size of 342) were included in nine kebeles.

To calculate sample size, main exposure variables such as maternal education and income were considered. Poverty was chosen as an independent variable since it gave maximum sample size as Compared to others. Poverty also affects under-5 mortality across all age groups: neonate, post-neonatal infants and children (2, 10). Cases were identified by the baseline survey which was conducted two months prior to the present study. House number and name of the household were used to find the cases. After finding the case, one control of the same age (+/-2 months) was selected from the next house (neighbor) using a code of house number in ascending order.

Data was collected using structured questionnaire. The questionnaire had two parts. In the first part, socioeconomic and proximate determinants of under-five mortality were addressed. In the proximate determinants, the following were included: reproductive factors, environmental determinants, behavioral factors which included practice, knowledge and perception based on Health Belief Model approach; nutritional factor (breast feeding pattern and practice), and child factor (immunization). Cause of death using verbal autopsy was considered in the second section. The verbal autopsy was adopted from World Health Organization (WHO) with some modification in accordance with the local situation (11). The questionnaire was first translated into Amharic and back retranslated into English by other experienced people to check its consistency. Important medical terminologies in the questionnaire were also translated into local language (Oromifa). The instrument was pretested in $10 \%$ of the sample size in the same population before it is used for the actual survey. Data was collected by trained high school completed persons who are involved in registration of vital events at the Field Research Center. The data collectors were trained for 2 days. Principal investigators strictly supervised data enumerators and the completeness of the questionnaire was checked every day.

To be edited, cleaned and analyzed, the collected data were entered into a computer using SPSS version-12 and Epi-Info 3.3.2 software. In the first setup Bivariate analysis was employed to see the association between proximate determinants versus socio-demographic variables and mortality. Then, to control the effect of confounding factors, logistic regression analysis was done. In the first model, socio-economic factors were considered whereas the second model included proximate determinants. In both models, variables were included based on their biological plausibility after reviewing different literatures and their $\mathrm{P}$-value $(\mathrm{P}<0.1)$ in the bivariate setup. The effect of breast feeding was assessed for children above 7 days of age to control for reverse of causality. Vaccination status was also assessed for children above 42 days since this variable is time dependent and most antigens are not given before 6 weeks. The final model was constructed using stepwise logistic regression method. Variables which showed statistically significant association in each model were included in the final model. Causes of death were determined using expert algorism from another study (12). The expert algorism incorporates major prevalent diseases in the country and is assumed to measure multiple causes of death. The expert algorism was validated in different developing countries (11). However, we didn't conduct validation study in the present study due to financial constraints.

\section{Operational definitions}

Knowledge:- Six knowledge questions were presented and correct answer was given score 1 and incorrect answer was given score 0 . The sum was computed and those who scored above the mean were labeled as having 'good knowledge'.

Perception:- Perceived severity, perceived susceptibility, perceived benefits and barriers were assessed using Likert Scale Method (1. strongly agree 2. agree 3. neutral 4. disagree 5. strongly disagree) and mean scores for each construct were computed and dichotomized into positive and negative. If a respondent scores below the mean she/he would be labeled as having positive perceived severity, susceptibility, benefits and barriers.

Practice:- Five questions related to practice were presented. These questions were related to use of foods or breast milk or home made fluids and/or Oral rehydration salt during illness, use of insecticide treated bed nets (ITN) and place of treatments when a child is sick. Correct answer was given score 1 and incorrect answer was given score 0 . The sum was computed and

Ethiop. J.Health Dev. 2007;21(2) 
those scoring above the mean were labeled as having 'good practice'.

Socio-economic status was assessed using wealth score which consisted of income, presence of latrine, safe water (water from tap water or protected well or spring) and radio. Income $>=100$ ETH Birr per month, presence of radio, latrine and safe water supply were given score one and other categories were given score 0 . The sum was computed and respondents who score above the mean were labeled as rich and respondents who scored below the mean were labeled as poor. Monthly income was dichotomized using 100 Birr as a cut off point. The rationale was that income $<100$ Birr per month was found to be strong predictor of infant survival around the same area (13). To calculate total monthly income, salary or other monthly income and annual income from production of common cereals in the area (teff, maize, sorghum, and pepper) were considered.

Written consent was obtained from the ethical clearance committee of Public Health Faculty of Jimma University and local administration of the Kebeles. Oral consent was obtained from the respondents. If there was any sick child, caretakers were advised to take the child to the nearest health institutions. Finally, the result was disseminated to the community and relevant government offices.

\section{Results}

In the baseline survey, a total of 185 under-five deaths were registered, making under-five mortality 130.9 per 1000. Neonatal and infant mortality rates were 38 and 76.4 per 1000 live births, respectively. From the total deaths, 168 (91\%) of them were included in the present study. Among 168 deaths, neonate ( $<=28$ days), postneonatal infants (29 to 359 days) and children (1-5 years) accounted $31.5 \%, 27.4 \%$ and $41.1 \%$ respectively.

For each case, one control from the neighbor was selected and which makes the total study population 336. The mean age of children was 17.7 months and males accounted for $59 \%$ of the study population. Ninety-five percent of the respondents were Oromo and Muslim. Majority of the mothers (96\%) were below elementary school. The mean age of respondents (mothers) was 28.3, $\mathrm{SD}=5.9$ (Table 1).

Causes of Death:- Since causes of death might have been different in neonatal from post-neonatal periods, the results were presented separately. The most common expected causes of death during neonatal period were pre-maturity, $26.4 \%$ (95\% CI: 15.8, 39.4); pneumonia, $22.6 \%$ (95\% CI: 12.8, 35.3); neonatal tetanus, $9.4 \%$ (95\% CI: 3.5, 19.6); and sepsis 7.5 \% (95\% CI: 2.4,
17.2). Fifteen percent of the causes of deaths were unspecified as depicted in Table 2.

Table 1: Socio-demographic characteristics of the respondents $(n=336)$, Gilgel Gibe Field Research Center, December 2005

\begin{tabular}{ll}
\hline Variables & Number (\%) \\
\hline Age of mothers(in years) & \\
$<20$ & $35(10.4)$ \\
$>=20$ & $301(89.6)$ \\
Ethnicity & $319(94.9)$ \\
$\quad$ Oromo & $14(4.2)$ \\
Yem & $2(0.6)$ \\
$\quad$ Gurage & $1(0.3)$ \\
$\quad$ Amhara & \\
Religion & $318(94.6)$ \\
$\quad$ Muslim & $16(4.8)$ \\
$\quad$ Orthodox & $2(0.6)$ \\
$\quad$ Protestant & \\
Educational status & $324(96.4)$ \\
$\quad$ Elementary and below & $12(3.6)$ \\
$\quad$ Above Elementary & \\
Monthly income(Birr) & $230(68.5)$ \\
$\quad<200$ & $106(31.5)$ \\
$\quad>=200$ & \\
Marital status & $324(96.4)$ \\
$\quad$ Married & $12(3.6)$ \\
$\quad$ Not married &
\end{tabular}

The top cause of death for infants older than 28 days and children were pneumonia, malaria, diarrheal diseases, and meningitis. As shown in Table 3, malaria is the second cause of death next to pneumonia for infants older than 28 days and the third cause of death next to pneumonia for children age 1 to 5 years. Diarrheal diseases (acute diarrhea, persistent diarrhea and dysentery) were the leading cause of death for children above 1 year. Severe malnutrition and measles were the two important contributing factors for $12 \%$ and $7 \%$ of deaths in post-neonatal period. Injury and HIV/AIDS accounted $3 \%$ and $2 \%$ of deaths respectively in children 1 to 5 years (Table-3).

Table2: Probable cause of neonatal deaths ( $n=53)$, Gilgel Gibe Field Research Center, December 2005

\begin{tabular}{lll}
\hline Causes & Number (\%) & $\mathbf{9 5 \% ~ C l}$ \\
\hline Prematurity & $14(26.4)$ & $(15.8,39.4)$ \\
Pneumonia & $13(24.5)$ & $(12.8,35.3)$ \\
Neonatal tetanus & $5(9.4)$ & $(3.5,19.6)$ \\
Sepsis & $4(7.5)$ & $(2.4,17.2)$ \\
Diarrhea & $4(7.5)$ & $(2.4,17.2)$ \\
Birth asphyxia & $3(5.7)$ & $(1.4,14.6)$ \\
Congenital malformation & $1(1.9)$ & $(0.09,8.9)$ \\
Meningitis & $1(1.9)$ & $(0.09,8.9)$ \\
Unspecified & $8(15)$ & $(7.2,26.6)$ \\
\hline
\end{tabular}




\begin{tabular}{lllll}
\multicolumn{6}{l}{ Table3: Probable causes of death of infants and children, Gilgel Gibe Field Research Center, December 2005 } \\
\hline Causes & Infants(n=46)+ & Children(n=69) & Combined+ & 95\% Cl of the \\
& No (\%) & No (\%)+ & No (\%) & \\
\hline Pneumbia & $22(47.8)$ & $24(34.8)$ & $46(42.2)$ & $(31.3,49.2)$ \\
Malaria & $19(41.3)$ & $20(29)$ & $39(37.1)$ & $(25.7,42.9)$ \\
Acute diarrhea & $12(26.1)$ & $22(31.9)$ & $34(30.1)$ & $(21.7,38.4)$ \\
Persistent diarrhea & 0 & $9(13)$ & $9(8.0)$ & $(3.8,13.8)$ \\
Dysentery & $4(8.7)$ & $4(5.8)$ & $8(7.1)$ & $(3.3,12.8)$ \\
Meningitis & $6(13.0)$ & $16(23.2)$ & $22(19.3)$ & $(12.7,13.0)$ \\
Severe malnutrition & $5(10.9)$ & $9(13)$ & $14(12.3)$ & $(7.1,19.1)$ \\
Measles & $2(4.3)$ & $6(8.7)$ & $8(7.1)$ & $(3.3,12.8)$ \\
Injury & 0 & $3(4.3)$ & $3(2.8)$ & $(0.6,6.9)$ \\
HIVIAIDS & 0 & $2(2.9)$ & $2(1.9)$ & $(0.3,5.6)$ \\
\hline
\end{tabular}

+ Sum may exceed the exact number of deaths and percentage may exceed 100 (the tool used is assumed to measure probable and multiple cause of death)

Determinants of Death:- Since marriage is universal, this variable was excluded from the analysis. There was no significant difference of death between males and females, OR=1.05 (95\%CI: 0.67, 1.67). Higher underfive mortality was observed among mothers whose educational level were elementary and below as Compared to mothers who were above elementary school, the OR being 11.7 (95\% CI: 1.5, 91). Other socio-demographic variables did not show statistically significant association with under-five mortality. Maternal education retained its significance after adjusting for other socio-demographic variables. Children who were born to mothers whose educational level is below elementary were 25 times more likely to die Compared to children who were born from mothers whose education is above elementary school, $\mathrm{OR}=24.8$ (95\% CI: 2.4, 290).

To assess the impact of breast feeding, the study was restricted to children older than 7 days to avoid including neonatal deaths that were not likely related to infant feeding mode. Children who were not breastfed were 6 times more likely to die compared to those who were breast fed. However, this finding was not statistically significant, OR=6.25 (95\% CI: 0.74, 52).

Since most of the antigens of vaccines are not given immediately after birth, the effect of vaccination was also assessed for children whose age was greater than 6 weeks. This might give the deceased children equal chance to be vaccinated as the survivors. Under-five mortality was highest for unvaccinated children compared to those who were vaccinated at least once, $\mathrm{OR}=4.43$ (95\% CI: 1.99, 9.85). After adjusting the major confounding variables, unvaccinated children were more likely to die Compared to the vaccinated ones, $\mathrm{OR}=5.13$ (95\% CI: 2.19, 11.97).

Higher risks of death of under-five children were observed while the next birth interval is less than 24 months, OR=2 (95\% CI: 1.19, 3.45). The other intermediate variables such as parity, birth order, age of mother at delivery, family planning utilization, housing conditions etc. were not significantly associated with under-five mortality. After controlling the effect of potential confounding variables, next birth interval was again significantly associated with under-five mortality. Children whose next birth interval is less than 24 months were 2.5 times more likely to die compared to those whose next birth interval is greater than 24 months, $\mathrm{OR}=2.46$ (95\% CI: $1.37,4.44)$.

Among the behavioral variables, high risk of under-five mortality were observed when the mothers had no good practice, negative perception on severity of illnesses, negative perception on benefits of some modern treatment. There was a statistically significant association between practice and perceived benefits with under-five mortality after controlling the effect of other variables. Mothers who had no much practices to common illnesses had 9 times more likely to have under-five mortality compared to mothers who had good practices, $\mathrm{OR}=8.97$ (95\% CI: 5.32, 15.29). Similarly, respondents who had negative perceived benefits towards modern treatment to common illnesses had 1.7 times more likely to have child deaths as compared with their counterparts, the OR being 1.74 (95\% CI: 1.01, 3.04) (Table-4).

The final model was constructed using stepwise logistic regression method. Variables which showed significantly associated in each model such as maternal education, birth interval, practice of mother, perceived benefits were included in the final model. Finally, maternal education, practice and perception of mother on the severity of illness and benefit of some treatment were found to be independent predictors of child survival. As shown in Table 5, children whose mothers were below elementary school were 14 times more likely to die compared to children whose mothers were above elementary school. Mothers who hadn't good practices had 4 times more likely to have child deaths compared to mothers who had 
good practices. Mothers who had negative perception on the severity of illness had 2 times more likely to have under-five mortality compared to mothers who had positive perception on the severity of illness. Similarly, respondents who had negative perception on the benefit of some treatment had 1.8 times more likely to have under-five mortality compared to mothers who had positive perception on the benefit of some treatment (Table-5).

Table 4: Behavioral determinants of under-five mortality ( $n=336)$, Gilgel Gibe Field Research Center, December 2005

\begin{tabular}{|c|c|c|c|c|}
\hline Variables & $\begin{array}{l}\text { Number of } \\
\text { cases }\end{array}$ & $\begin{array}{l}\text { Number of } \\
\text { controls }\end{array}$ & Crude OR (95\% Cl) & Adjusted OR (95\% Cl) \\
\hline \multicolumn{5}{|l|}{ Practice* } \\
\hline Good & 40 & 60 & 1 & 1 \\
\hline Not good & 128 & 50 & $7.31(4.51,11.85)^{\star \star}$ & $8.97(5.32,15.29)^{\star \star}$ \\
\hline \multicolumn{5}{|c|}{ Perceived susceptibility } \\
\hline Positive & 102 & 114 & 1 & 1 \\
\hline Negative & 66 & 54 & $1.36(0.87,2.14)$ & $1.42(0.77,2.59)$ \\
\hline \multicolumn{5}{|l|}{ Perceived severity } \\
\hline Positive & 86 & 101 & 1 & 1 \\
\hline Negative & 82 & 67 & $1.44(0.93,2.24)$ & $1.72(0.95,3.08)$ \\
\hline \multicolumn{5}{|l|}{ Perceived benefits } \\
\hline Positive & 88 & 114 & 1 & 1 \\
\hline Negative & 80 & 54 & $1.92(1.23,2.99)^{\star *}$ & $1.74(1.01,3.04)^{\star \star}$ \\
\hline \multicolumn{5}{|l|}{ Perceived barrier } \\
\hline Positive & 98 & 100 & 1 & 1 \\
\hline Negative & 70 & 68 & $1.07(0.69,1.66)$ & $0.99(0.58,1.69)$ \\
\hline \multicolumn{5}{|l|}{ Knowledge } \\
\hline Satisfactory & 90 & 95 & 1 & 1 \\
\hline Not satisfactory & 78 & 73 & $1.11(0.71,1.69)$ & $0.84(0.50,1.42)$ \\
\hline
\end{tabular}

* The total number may not be equal to 336 since some of the controls were not sick and questions related to practice were not applicable for these controls.

** P-value $=0.0001$

Table5: Factors independently associated with under-five mortality ( $\mathbf{n}=\mathbf{3 3 6}$ ), Gilgel Gibe Field Research Center, December 2005

\begin{tabular}{lllll}
\hline Variables & $\begin{array}{l}\text { Number of } \\
\text { cases }\end{array}$ & $\begin{array}{l}\text { Number of } \\
\text { controls }\end{array}$ & $\begin{array}{l}\text { Crude OR } \\
(95 \% \mathrm{Cl})\end{array}$ & $\begin{array}{l}\text { Adjusted OR } \\
(95 \% \mathrm{CI})\end{array}$ \\
\hline $\begin{array}{l}\text { Maternal Education } \\
\quad \text { Above elementary }\end{array}$ & 1 & 11 & 1 & 1 \\
$\quad \begin{array}{l}\text { Elementary and below } \\
\text { Practice }\end{array}$ & 167 & 157 & $14.7(1.49,91.6)$ & $14.29(1.59,228.30)$ \\
$\quad$ Good & 40 & 60 & 1 & 1 \\
$\quad$ Not good & 127 & 50 & $7.31(4.51,11.85)$ & $4.58(2.59,8.07)$ \\
$\begin{array}{l}\text { Perceived benefits } \\
\quad \text { Positive }\end{array}$ & 88 & 114 & 1 & 1 \\
$\quad$ Negative & 80 & 54 & $1.92(1.23,2.99)$ & $1.84(1.04,3.23)$ \\
$\begin{array}{l}\text { Perceived severity } \\
\quad \text { Positive }\end{array}$ & 86 & 101 & 1 & 1 \\
$\quad$ Negative & 82 & 67 & $1.44(0.93,2.24)$ & $2.18(1.22,3.87)$ \\
\hline
\end{tabular}

\section{Discussions}

There have been a few studies on the determinants and immediate cause of death related to under-five children in Africa. Population based case-control study such as the present study is the method of choice to ascertain determinants and immediate causes of death in developing countries like Ethiopia. This study has provided pertinent information about the causes and determinants of death in under-five children for decision makers. The study also tried to control many confounding variables. However, it might have some limitation such as recall bias on symptoms of illness and risk factors. Misclassification of cases in some diseases might occur due to less sensitivity and specificity of the verbal autopsy tools. 
Infant mortality rate (IMR) seems to be declining as compared to that of the national and other community based studies conducted in Butajira and southwestern Ethiopia a decade back. However, neonatal mortality rate is even higher than the figure which was obtained a decade back $(14,15)$. This could be due to lack of intervention strategies which focus on neonatal survival. In using verbal autopsy questions, multiple causes of deaths might be possible due to the same environmental or behavioral factors or existence of co-morbidity by chance. Measles and malnutrition, for example, can be further complicated by diarrheal diseases or pneumonia. Some diseases like measles and neonatal tetanus, which have very distinctive symptoms, can be diagnosed with high sensitivity and specificity using verbal autopsy. However, systemic diseases such as malaria, which has no particularly distinctive features, and shares many symptoms with other common childhood diseases such as acute lower respiratory infections, might be diagnosed with low sensitivity as observed in other studies (11).

In our study, prematurity, pneumonia, neonatal tetanus and sepsis were the major causes of deaths during neonatal periods which has similarity to other studies (10, 16). Neonatal tetanus which is eliminated in many middle-income countries is still the major cause of death in the study setting. This could be due to low coverage of vaccination of mother with tetanus toxoid and high prevalence of unskilled deliveries as observed in the baseline survey (8). Significant numbers of neonatal deaths were unspecified which could be due to recall bias. The major causes of deaths in post-neonatal periods were pneumonia, diarrheal diseases, malaria and meningitis. This finding is consistent with other studies $(10,17)$.

Severe malnutrition and measles respectively accounted about $12.3 \%$ and $7.1 \%$ of deaths in post-neonatal period. Though we did not assess all forms of malnutrition the prevalence of malnutrition as underlying causes of death is low as compared to other studies (2). Several factors such as indoor air pollutions, health seeking behavior, accessibility and utilization of health services could contribute to the high burden of pneumonia in the study settings. Malaria is becoming the major cause of death in post-neonatal periods. This could be due to the appearance of Gilgel Gibe Dam, artificial lake which is favorable environmental conditions for malaria, and low utilization preventive measures such as usage of treated bed nets for under-five children. It was observed that communities around the artificial lake were more likely to have epidemics of malaria (18). This might need further study on the effect of the dam on the incidence of malaria. The fact that malaria is not suitable for verbal autopsy due to its non-specific presentation might also obscure its true prevalence. Based on pediatrics case definition, HIV/AIDS is contributing about $2 \%$ of post neonatal deaths. In other study, HIV/AIDS accounted 3\% of under-five deaths (2) whereas in our study, the prevalence might be underestimated because HIV/AIDS is not suitable for verbal autopsy due to its nondistinctive features.

Among the socio-economic factors, maternal education was significantly associated with under-five mortality. This fact had been confirmed by different literatures in different countries $(3,19-23)$. However, the very wide confidence interval of the odds ratio of maternal education in the present study is an indicative of inadequate sample size. Under-five mortality was doubled in mother less than 20 years of age compared to above 20 years as observed in other studies $(23,24)$.

Among the intermediate variables, vaccination status of the child and next birth interval were significantly associated with under-five mortality. Breast-feeding was also protective of under-five mortality although it was not significant. This non-significant finding in our study could be due to small sample size. The importance of breast-feeding and vaccination as protective factors of under-five mortality were mentioned in different literatures $(10,24-28)$. Next birth interval was significantly associated with under-five mortality. The attention of mothers to the newborn baby and neglecting the older sibling in giving care might have contributed to the high number of death of the older children. Family planning and antenatal care follow-up were not associated with under-five mortality, unlike other studies (19). This could be explained by homogeneity of the study population with respect to these variables. None of the environmental risk factors were associated with mortality which is in contrast to other studies $(17,19)$. The main reason could be either due to similarity of the study population with respect to most of the environmental variables especially housing conditions or source of water for drinking.

The effects of behavioral variables on survival of children were assessed using health belief model. Good practice and positive perception of mothers on the severity of illness and benefit of some treatment were protective for under-five mortality. Although it was not based on health belief models, some practices such as no action for diarrhea, acute respiratory infections and malaria were associated with high mortality in the Butajira study and other study elsewhere (2, 29). Positive perceived benefits for some treatments were found to be protective of under-five mortality. Mothers who had positive Perceived severity and benefits were more likely to take the aforementioned actions. Mothers who had negative perception on the above actions might seek help from traditional means which might not be helpful for the survival of the child. In the final model, most of the variables which were statistically significant in each component of the conceptual framework retained their significance. Maternal education, practice, perception on 
benefits of some treatment and severity of illnesses are the predictors of under-five survival.

In conclusion, neonatal mortality rate has increased as compared to the result of other study conducted a decade back around the same area. The major causes of death in under-five children are pneumonia, malaria, diarrheal diseases, low birth weight, meningitis and neonatal tetanus. Among many variables, vaccination status, maternal education, practice and perception of mothers on severity of common illness and benefits of some modern treatment were the best predictor of under-five mortality. Cognizant of this fact, we recommend that mothers should be trained to practice key child survival interventions like antenatal care follow-up, skilled-based delivery, use of oral rehydration salt and home made fluids, vaccination and impregnated bed nets (ITN).The literacy status of women should be improved so that they can care their children for better child survival.

\section{Acknowledgment}

We extend our appreciation to the community groups in the study area and their leaders in providing the necessary information. The study was funded by Public Health Faculty of Jimma University.

\section{Reference}

1. Ahmad O, Lopez A, Inoue M. The decline in child mortality: a reappraisal. Bulletin of World Health Organization,2000,78:1175-1191.

2. Black R, Morris S, Bryce J. Where and why are 10 million children dying every year? Lancet 2003;361:2226-34

3. Central Statistical Authority (CSA). Demographic and health survey, 2000

4. Ministry of Health, Federal Democratic of Ethiopia. Health and health related indicators, 2004/2005

5. UN, General Assembly., 56 ${ }^{\text {th }}$ session. Road map towards the implementation of the united nation millennium declaration: report of the Secretary General (UN document no: A/56326). New York: United Nations, 2001.

6. Mosley WH, Chen L. An analytical framework for the study of child survival in developing countries, Population and Development Review 10 (supplement), 1984.

7. The Federal Democratic Republic of Ethiopia, Ministry of Mines and Energy. Gilgel Gibe Project. Environmental impact assessment, Addis Ababa, 1997

8. Assefa M, Tessema F, Tegegn A, Alemayehu E. Establishing field epidemiology laboratory in four woredas around the Gilgel Gibe hydroelectric dam, January, 2006.

9. Girma B, Berhane Y. Epidemiological assessment of determinants of under-five mortality in Jimma town. A thesis for master of public heath, Addis Ababa University, 2005(unpublished).
10. Kiros G, Hogan D. War, famine and excessive child mortality in Africa. The role of parental education. International Journal of Epidemiology, 2001:447456

11. Anker N, Black R, Coldhan C etal. A standard verbal autopsy methods for investigating cause of death in infants and children, WHO, 1999

12. Aguilar, Ana Maria, Ruth Alvarado, Dilberth Cordero, Patrick Kelly, Adalid Zamora, and Ren ${ }^{\mathrm{TM}}$ Salgado. Mortality survey in Bolivia: The final report. Investigating and identifying the causes of death for children under-five. USAID, the basic support for institutionalizing child survival (BASICS) Project. ,1998 ,Arlington, Va

13. Asefa M, Drewett R, Tessema F. A birth cohort study to identify risk factors associated with infant mortality that are amenable to intervention. Ethiop. J.Health Dev,2002, 16(special issue):13-20

14. Assefa M, Tessema F. Infant survivorship and occurrence of multiple births: A longitudinal community based study, south west Ethiopia. Ethiop.J.Health.Dev.2002;16(special issue);5-11

15. Anderson T, Berhane Y, Walls S, Hogburg U. The impact of neonatal mortality on subsequent survival in rural Ethiopia. Ann Tropical pedeatr, 2002; 22(1): 25-32

16. Lawn J, Cusens S, Zupan J. Four million neonatal deaths: when?where?why?. The lancet neonatal survival. http://wwww.thelancet.com(accessed September 15,2005)

17. Shamebo D, Sandstrom A, Muhe L, Freji L, Krantz I, Lonnberg G, Wall S. The Butajira project in Ethiopia: a nested case-referent study of under-five mortality and its public health determinants. Ethiop.J.Health.Dev,1994;8 (special issue),1994:389-395

18. Deribew A, Alemseged F, Assefa D, Wondimu T. Establishing viable surveillance system in the communities around Gilglel Gibe. Jimma University, December 2005 (unpublished report of field epidemiology activity)

19. Assefa M, Tessema F. Infant survivorship and occurrence of multiple births: A longitudinal community based study, south west Ethiopia. Ethiop.J.Health.Dev.2002;16(special issue);5-11

20. Democratic Republic of Yemen, CSA. Demographic and maternal and child health survey, 1997

21. Oni G.A. Child mortality in a Nigerian city: its levels and socio-economic differentials. Social science and medicine,1988, 27:607-614

22. Aksit B, and Aksit B. Socio-cultural determinants of infant and child mortality in Turkey. Science and Medicine,1989, 28:571-576

23. Wool Bright L. Post neonatal mortality in Alabama: Why no progress in the 90s? Ann epidemiol, 2001; 11:208-212

24. Binka FN, Maude GH, Gyapong M, Ross DA, Smith PG. Risk factors for child mortality in Northern

Ethiop. J.Health Dev. 2007;21(2) 
Ghana-A case-control study. International Journal of Epidemiology,1995;24 (1):127-135

25. Betran AP, Onis M, Lauer JA, Villar J. Ecological study of effect of breast feeding on infant mortality in Latin America. Br Med J 2001;323:1-5.

26. WHO Collaborative Study Team on the role of breastfeeding on the prevention of infant mortality effect of breastfeeding on infant and child mortality due to infectious diseases in less developed countries: A pooled analysis. Lancet 2000;355:451-5.

27. Victora CG, Huttly SR, Fuchs SC, et al. Deaths due to dysentery, acute and persistent diarrhoea among Brazilian infants. Acta Paediatr suppl 1992;381:711.
28. Victora CG, Smith PG, Vaughan JP, etal. Infants feeding and detaths due to diarrhea: a case-control study. Am J Epidemiol, 1989;129:1033-41.

29. Shamebo D, Muhe L, Sandstrom A, Freij L, Krantz I, Wall S. The Butajira project in Ethiopia: a nested case-referent study of under-five mortality and its health and behavioral determinants. Ethiop. J. Health. Dev, 1994;8(special issue),1994:201-209. 